\title{
WATER VAPOR, CLOUD AND AEROSOL PROPERTIES ON THE TIBETAN PLATEAU USING MULTI-LIDAR MEASUREMENTS
}

\author{
Songhua WU*, Guangyao DAI, Dongxiang WANG, Xiaochun ZHAI, Xiaoquan SONG \\ Ocean Remote Sensing Institute, Ocean University of China, Qingdao 266100, China. \\ *Email:wush@ouc.edu.cn
}

\begin{abstract}
The $3^{\text {rd }}$ Tibetan Plateau atmospheric expedition experiment campaign were operated in the Tibetan Plateau during July and August 2014 by utilizing the Water vapor, Cloud and Aerosol Lidar (WVCAL), Coherent Doppler Wind Lidar and ceilometer VAISALA CL31. The observation was carried out in Nagqu area $\left(31.5^{\circ} \mathrm{N}, 92.05^{\circ} \mathrm{E}\right)$, which is 4508 meters above the mean sea level. Water vapor mixing ratio, cloud height, vertical wind speed and vertical water vapor flux was measured by these lidars. The inversion methods of data products of lidars are described in details in this paper. Furthermore, the clouds heights measured by lidar and ceilometer were compared to verify the performance of the lidar. Finally, the case studies of water vapor mixing ratio, water vapor flux and cloud height and statistics were provided.
\end{abstract}

\section{INTRODUCTION}

The Tibetan Plateau is located in a critical and sensitive junction of four climatic systems: the Westerlies, the East Asian Monsoon, the Siberian cold polar airflow, and the Indian monsoon. In turn, the Tibetan Plateau influences the atmosphere in East Asia area and even the whole northern hemisphere.

Water vapor is the most active element and has great impact on the change of the climate and weather. It influences atmospheric circulation and temperature structure by condensation and evaporation processes. Together with water vapor, aerosol and clouds play an important role in the global energy budget and radiative forcing both directly and indirectly. Due to the important influence and the rareness of measurement, the observation of these compositions at the Tibetan Plateau becomes significant and urgent. Aiming at the detection of water vapor mixing ratio, Raman technique is applied. Raman Lidar technique depends on the detection of Raman backscattered radiation from atmospheric molecules ${ }^{[1,2]}$. The process of Raman scattering is characterized by a wavelength shift of the scattered radiation in respect to the exciting wavelength. The shift is uniquely associated with the internal transitions between the rotational-vibrational energy levels of the molecules ${ }^{[3]}$. This technique was firstly used by Melfi and Cooney ${ }^{[1]}$ and the profiles of water vapor mixing ratio was retrieved. Due to the development of the high power laser source, the vertical operation range of the Raman Lidars can be extended up to $7 \mathrm{~km}^{[4]}$ and throughout the troposphere ${ }^{[5]}$. Raman Lidars with high power source can also measure atmospheric boundary layer for a complete diurnal cycle with high resolution spatial and temporal resolutions ${ }^{[6]}$.

When come to the measurement and classification of the aerosol and clouds, the polarization Lidar technique is a well-established method ${ }^{[7,8]}$. The polarization Lidar technique bases on the depolarization character of light and the particles scattered radiation. This technique is widely used in the identification of clouds types, desert dust, volcanic ash ${ }^{[9]}$. It is also helpful to improve the estimation of the microphysical properties of dust from optical measurements ${ }^{[10]}$.

In order to study the boundary layer dynamics on plateau, the wind field needs to be observed. A pulsed coherent Doppler wind Lidar was used to measure the wind profile and vertical velocity in the boundary layer accurately to understand the unique property of atmospheric circulation and hydrological cycling on the Tibetan Plateau.

\section{METHODOLOGY}

\subsection{WATER VAPOR MIXING RATIO}

The Lidar equation can be described as

$$
\begin{aligned}
& P\left(z, \lambda_{R}\right)+P_{B R}= \\
& P_{0}\left(\lambda_{L}\right) \Delta z \frac{A_{0} O(z)}{z^{2}} \xi\left(\lambda_{R}\right) \beta_{R}^{\pi}\left(z, \lambda_{R}\right) T^{u p}\left(z, \lambda_{L}\right) T^{d o w n}\left(z, \lambda_{R}\right)
\end{aligned}
$$




$$
\begin{aligned}
& T^{u p}\left(z, \lambda_{L}\right)=\exp \left[-\int_{z_{0}}^{z} \alpha\left(z^{\prime}, \lambda_{L}\right) d z^{\prime}\right] \\
& T^{\text {down }}(z, \lambda)=\exp \left[-\int_{z}^{z_{0}} \alpha\left(z^{\prime}, \lambda_{L}\right) d z^{\prime}\right]
\end{aligned}
$$

Where $P_{0}\left(\lambda_{L}\right)$ is the laser pulse energy, $\Delta z$ is the range resolution, $A_{0}$ is the aperture of the telescope, $\xi\left(\lambda_{R}\right)$ is the receiving efficiency at a given wavelength, $\beta_{R}^{\pi}\left(z, \lambda_{R}\right)$ is the backscatter coefficient at $\lambda_{R}, \alpha\left(z, \lambda_{L}\right)$ is the extinction coefficient, $T^{u p}\left(z, \lambda_{L}\right)$ and $T^{\text {down }}\left(z, \lambda_{R}\right)$ are the atmospheric transmission at $\lambda_{L}$ and $\lambda_{R}$ respectively.

According to equation (1), the backscatter signal of $\mathrm{N}_{2}$ and $\mathrm{H}_{2} \mathrm{O}$ are obtained as $P\left(z, \lambda_{\mathrm{N}_{2}}\right)$ and $P\left(z, \lambda_{\mathrm{H}_{2} \mathrm{O}}\right)$. The water vapor mixing ratio can be calculated by equation (3):

$$
w(z)=C \frac{P\left(z, \lambda_{\mathrm{H}_{2} \mathrm{O}}\right)}{P\left(z, \lambda_{\mathrm{N}_{2}}\right)} \Delta T\left(\lambda_{\mathrm{N}_{2}}, \lambda_{\mathrm{H}_{2} \mathrm{O}}, z\right)
$$

Where: $C$ is Raman channel constant and can be obtained by contrast of Lidar data and radiosonde data, $\Delta T\left(\lambda_{\mathrm{N}_{2}}, \lambda_{\mathrm{H}_{2} \mathrm{O}}, z\right)$ is the differential atmospheric transmission at nitrogen and water vapor wavelengths and is calculated by equation (4):

$$
\begin{aligned}
& \Delta T\left(\lambda_{N_{2}}, \lambda_{H_{2} O}, z\right)= \\
& \exp \left(-\int_{z_{0}}^{z}\left[\alpha\left(z^{\prime}, \lambda_{N_{2}}\right)-\alpha\left(z^{\prime}, \lambda_{H_{2} O}\right)\right] d z^{\prime}\right)
\end{aligned}
$$

We assume that the relationship between Lidar data $W_{\text {Lidar }}=\frac{P\left(z, \lambda_{\mathrm{H}_{2} \mathrm{O}}\right)}{P\left(z, \lambda_{\mathrm{N}_{2}}\right)} \Delta T\left(\lambda_{\mathrm{N}_{2}}, \lambda_{\mathrm{H}_{2} \mathrm{O}}, z\right)$ and radiosonde data $W_{\text {Sonde }}$ as equation (5):

$$
W_{\text {Sonde }}=C^{*} W_{\text {Lidar }}+D
$$

After the calibration and validation using the radiosonde data, the water vapor mixing ratio can be rewritten as

$$
W_{\text {Lidar }}^{\text {Cal }}=218.9976 * W_{\text {Lidar }}-0.33976
$$

\subsection{VERTICAL VELOCITY VERTICAL WATER VAPOR FLUX}

AND

The Coherent Doppler lidar takes advantage of the fact that the frequency of the echo signal is shifted compared to the local-oscillator light because of the Doppler effect which occurs from backscattering of aerosols. The Doppler shift in the frequency of the backscattered signal is analyzed to calculate the line-of-sight (LOS) velocity component of the air motion. The Doppler shift $f_{D}$ can be obtained by equation (7):

$$
f_{D}=\frac{2\left|\stackrel{\mathbf{u}}{V}_{L O S}\right|}{\lambda}
$$

Where $\stackrel{\mathbf{u}}{V}$ LOS $_{\text {is }}$ the line-of-sight (LOS) velocity, $\lambda$ is the laser wavelength and is equal to $1550 \mathrm{~nm}$ in this lidar system.

When the LOS velocities in four directions $\stackrel{\mathbf{u}}{V}_{L O S, E}$, $\stackrel{\mathbf{u}}{V}_{L O S, W}, \stackrel{\mathbf{u}}{V}_{L O S, S}$ and $\stackrel{\mathbf{u}}{V}_{L O S, N}$ were measured, the vertical wind speed can be calculated by equation $(8):^{[11]}$

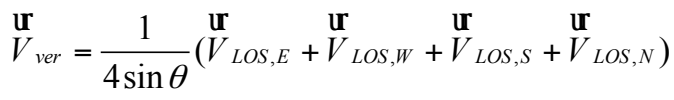

Where $\theta$ is the elevation.

With the synchronized observations of the water mixing ratio and vertical velocity, the vertical water vapor flux $F l u x_{W V, v e r}$ can be calculated by equation (9):

$$
\operatorname{Flux}_{W V, v e r}=\rho_{W V} *||_{v e r}^{\mathbf{u}} \mid
$$

Where $\rho_{W V}$ is the absolute humidity that can be obtained from the water vapor mixing ratio.

\subsection{CLOUD HEIGHT MEASUREMENT AND CLOUD STATISTICS}

WVCAL is capable of detecting of cloud height. For purpose of determining the cloud height, the algorithm that combines "differential zerocrossing algorithm" ${ }^{[12]}$ and "threshold algorithm" ${ }^{[13]}$ is taken into account. Generally cloud height can be determined directly from these zero crossings of the first derivative of backscatter intensity $d P(z) / d z$. However, in order to exclude interference of spurious zero crossings, The $d P(z) / d z$ is determined from a least-squares fit by using a multipoint window that slides through successive points from $z_{0}$ to the end of the lidar profile. Besides, a range-dependent threshold is defined, based on the noise in the recorded lidar signal. Signal excursion above the threshold value is identified as a cloud. By this algorithm, cloud layers apparent in the return signal are identified. However, if the lower clouds were too thick to be 
penetrated, the higher clouds will not be detected and cannot be identified.

\section{RESULTS}

Here we provide case studies of water vapor mixing ratio in Fig. 1. Several intercomparisons of lidar derived vertical profiles with radiosondes are presented. In this figure, the green line indicates the water vapor mixing ratio measured by lidar and the pink line shows the error bar of the data. Meanwhile the blue line shows the data of radiosonde. From these figures, one dry layer could be seen at about $2.8 \mathrm{~km}$ to $3 \mathrm{~km}$ in left figure and one distinct wet layer could be seen at about $2.5 \mathrm{~km}$ to $3 \mathrm{~km}$ in the right figure. All of the water vapor mixing ratio profiles was averaged every 60 minutes and the range resolution was $75 \mathrm{~m}$.
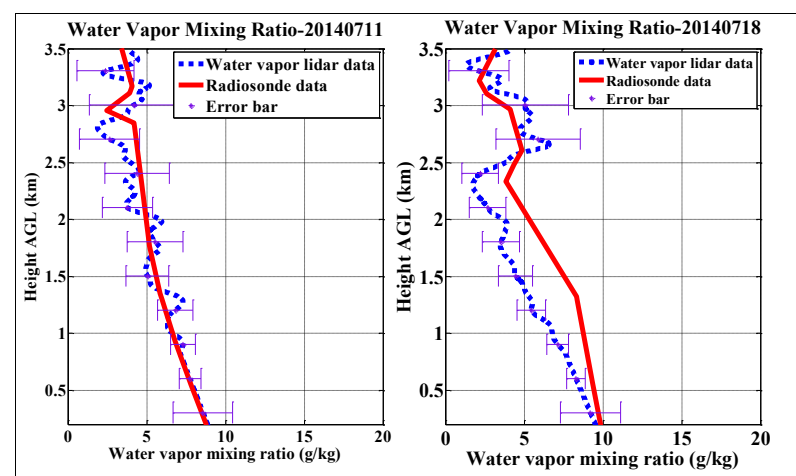

Fig.1. Water vapor mixing ratio study cases in Nagqu on 11 and 18 July 2014.

In term of the vertical velocity and vertical water vapor flux, one case study on 15 August 2014 is presented below. Fig. 2 is the time serials of the vertical velocity profile of 164 minutes obtained from the Coherent Doppler Wind Lidar. By combining absolute humidity and vertical velocity data, the vertical water vapor flux can be calculated and the temporal development is shown in Fig. 3.

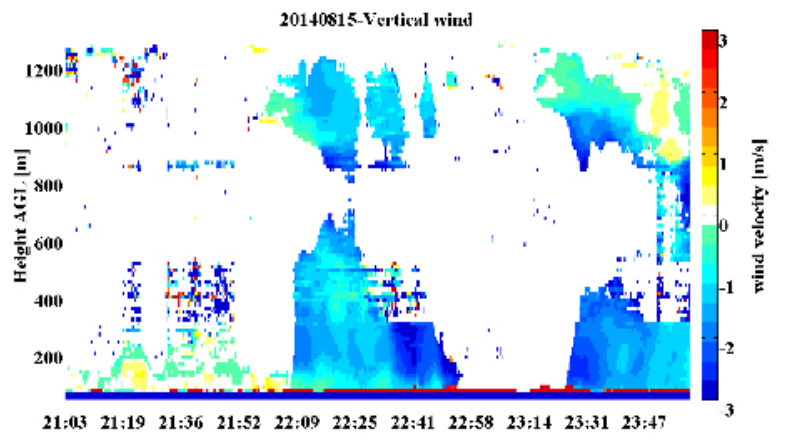

Fig.2. Time serials of vertical velocity profile.

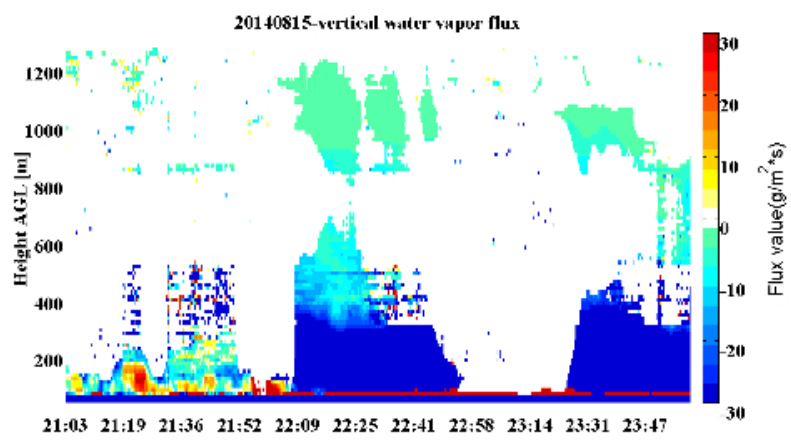

Fig.3. time serials of vertical water vapor flux.

The cloud heights measured by WVCAL and VAISALA CL31 ceilometer are compared. One case study on 18 July 2014 is presented. From the results on that day, it can be figured out that the correlation coefficient and standard deviation of cloud heights measured by polarization channel and infrared channel of Lidar were $91.87 \%$ and $0.28 \mathrm{~km}$ respectively. Meanwhile, the correlation coefficient and standard deviation of cloud heights measured by polarization channel of Lidar and VAISALA were $80 \%$ and $0.37 \mathrm{~km}$ respectively.

Lastly, the cloud statistics in Nagqu is shown in Fig. 4. The number and frequency of clouds layers are analyzed based on the 3rd Tibetan Plateau atmospheric expedition experiment campaign from July to Augest, 2014. The frequency of cloud appearance was about $59.88 \%$ in summer at the observatory.

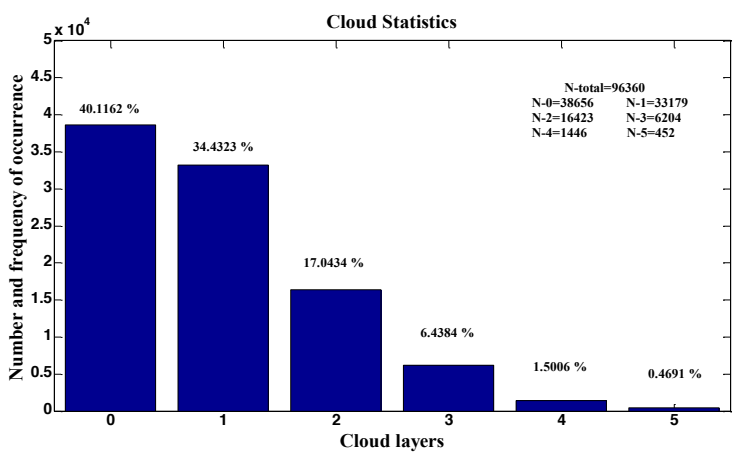

Fig.4. Cloud statistics in Nagqu from Jul 8, 2014 to August 16, 2014

\section{CONCLUSIONS}

By utilizing WVCAL, information about water vapor was acquired. Result from the abundant vegetation, lakes effect and wet Indian monsoon 
and East Asia monsoon, water vapor mixing ratio in Tibetan plateau in summer was rich.

With the help of the WVCAL and the Coherent Doppler Wind Lidar, the vertical wind speed and vertical water vapor flux were calculated. The upwelling and deposition of the water vapor were monitored.

The cloud base height measured by $532 \mathrm{~nm}$ channel, $1064 \mathrm{~nm}$ channel of Lidar and VAISALA CL31 can match well and the correlation coefficient of each other was larger than $80 \%$. However, because of the difference in emission wavelengths, deviation of cloud base height exists. The standard deviation was about 0.2 to $0.4 \mathrm{~km}$ and was acceptable.

Cloud statistics was provided during 3rd Tibetan Plateau atmospheric expedition experiment campaign in Nagqu, 2014. The frequency of cloud appearance was about $59.88 \%$. Consequently, clouds in Nagqu were abundant in summer.

\section{ACKNOWLEDGEMENT}

This work was funded by CAMS/LAWS (Chinese Academy of Meteorological Science/Lab oratory of Severe Weather)

\section{REFERENCES}

[1] Dinoev, T., 2009: Automated Raman lidar for day and night operational observation of tropospheric water vapor for meteorological applications(Doctoral dissertation, ÉCOLE POLYTECHNIQUE FÉDÉRALE DE LAUSANNE).

[2] Renaut, D., \& Capitini, R., 1988: Boundarylayer water vapor probing with a solar-blind Raman Lidar: validations, meteorological observations and prospects, Journal of Atmospheric and Oceanic Technology, 5(5), 585601.

[3] Demtroder, W., \& Demtroder, W., 2005: Molecular physics: theoretical principles and experimental methods, Wiley $\mathrm{VCH}$.

[4] Whiteman, D. N., Melfi, S. H., \& Ferrare, R. A., 1992: Raman Lidar system for the measurement of water vapor and aerosols in the Earth's atmosphere, Applied Optics, 31(16), 30683082.
[5] Goldsmith, J. E. M., Blair, F. H., Bisson, S. E., \& Turner, D. D., 1998: Turn-key Raman Lidar for profiling atmospheric water vapor, clouds, and aerosols, Applied Optics, 37(21), 4979-4990.

[6] Froidevaux, M., Higgins, C. W., Simeonov, V., Ristori, P., Pardyjak, E., Serikov, I., ... \& Parlange, M. B., 2013: A Raman lidar to measure water vapor in the atmospheric boundary layer. Advances in Water Resources, 51, 345-356.

[7] Ansmann A., Tesche M., Althausen D., et al., 2008: Influence of Saharan dust on cloud glaciation in southern Morocco during the Saharan Mineral Dust Experiment, Journal of Geophysical Research: Atmospheres (19842012), 113(D4).

[8] Freudenthaler, V., Esselborn, M., Wiegner, M., Heese, B., Tesche, M., Ansmann, A., ... \& Seefeldner, M., 2009: Depolarization ratio profiling at several wavelengths in pure Saharan dust during SAMUM 2006. Tellus B,61(1), 165179.

[9] Sassen, K., Zhu, J., Webley, P., Dean, K., \& Cobb, P., 2007: Volcanic ash plume identification using polarization lidar: Augustine eruption, Alaska. Geophysical Research Letters, 34(8).

[10] Wiegner M, Gasteiger J, Kandler K, et al., 2008: Numerical simulations of optical properties of Saharan dust aerosols with emphasis on lidar applications. Tellus B, 61(1), 180-194.

[11] Cariou, J. P., \& Boquet, M., 2011: Leosphere pulsed lidar principles. Leosphere, Orsay (FR), 132.

[12] Pal, S. R., Steinbrecht, W., \& Carswell, A. I., 1992: Automated method for lidar determination of cloud-base height and vertical extent, Applied optics, 31(10), 1488-1494.

[13] Winker, D. M., \& Vaughan, M. A., 1994: Vertical distribution of clouds over Hampton, Virginia observed by lidar under the ECLIPS and FIRE ETO programs, Atmospheric research, 34(1), 117-133. 